\title{
Simple data analyser for laboratory statistics
}

\section{PETER A. CLARK From the Department of Pathology, Barnet General Hospital, Barnet, Herts}

The recent requirement by the Ministry of Health that pathology laboratories should prepare detailed statistics of the origin and type of each request has prompted construction of a simple data analyser.

The device, shown in Fig. 1, consists of a bank of magnetic counters actuated by two series of switches. The first set of push switches, of the interlocking type found on tape recorders, denotes the origin of a request, e.g., main hospital, general practitioners. Any one of these switches will lock down in the 'on' position. The second series of switches are ordinary push buttons and denote type of specimen, e.g., haematology, biochemistry. Each

Received for publication 7 September 1965.

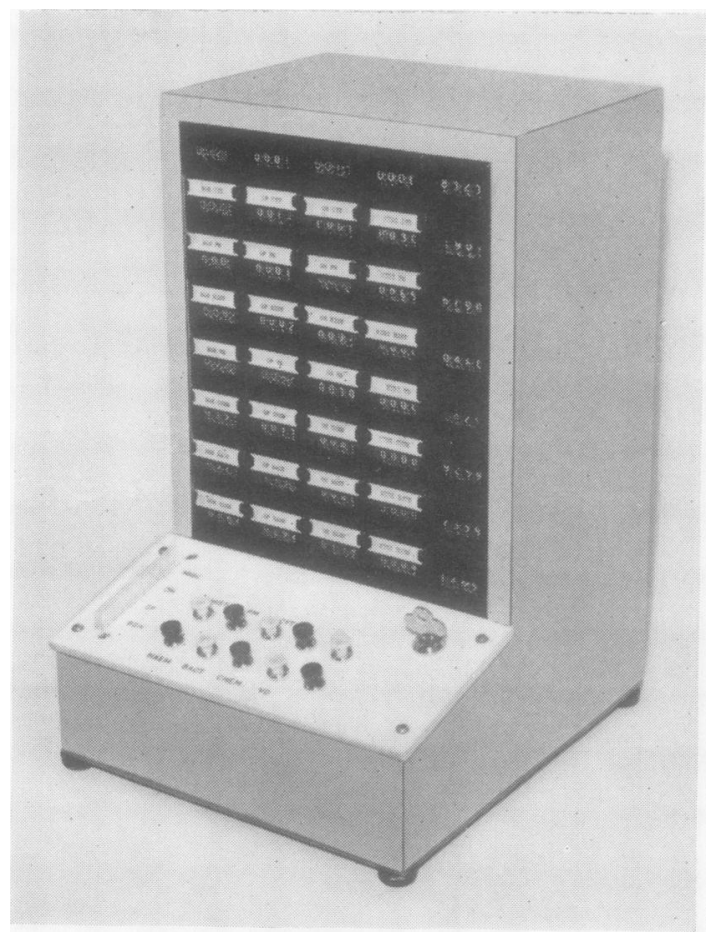

FIG. 1. The data analyser. type of origin and request has an individual counter which can only be actuated when both the appropriate push switch and button from each series is depressed.

\section{CONSTRUCTION OF THE DEVICE}

Forty ex G.P.O. magnetic counters are used. These ma be purchased on the surplus market at prices betweed 3s. and $12 \mathrm{~s}$. 6d. each, the more expensive ones being neva The push switches and buttons are standard items readily available. The power supply consists of a sma $\$$ transformer giving 50 volts at about 500 ma with futt wave rectification by silicon diodes. (Other types $g \rho$ counters may have different power supply requirements A key switch is incorporated in the main supply to preverp unauthorized use. A small silicon diode is used in series with each counter in order to prevent actuation of mores than one counter at a time. These diodes were broughiv from a surplus store at $1 \mathrm{~s}$. each. The circuit is shown in Figure 2. The whole equipment is built into a case made of $\frac{1}{2}$ in. plywood covered with Formica.

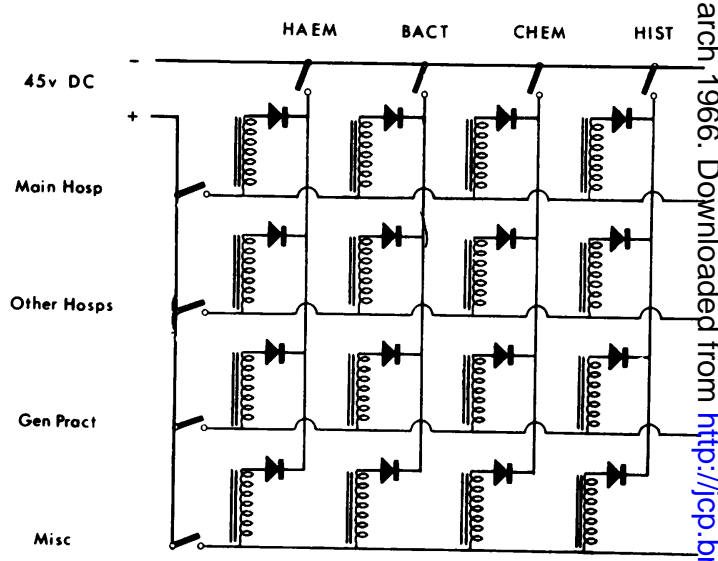

FIG. 2. The circuit: for clarity, only 16 counters are showr

This apparatus has proved very satisfactory in use and a day's requests may be analysed in a few minutes. The counters used have no zero reset and their initial reading $\$$ must be recorded before each quarterly counting period If zero readings are required a simple motor-drivem switch has been devised which actuates the counters about 200 times per minute until zero is reached.

The whole device has been made at a cost of about $£ 15 \mathrm{~N}$

I would like to thank my colleagues Dr. R. F. Welch Dr. D. M. H. Cogman, and Mr. D. P. Winks for theif help in the design and construction of this device. 